\title{
Collaboration: Finding our Way Within, Around, and Through
}

\author{
Kerry E. Robertson \\ University of Victoria
}

In the fall of 2017, I began my doctoral studies, three decades after starting my teaching career. As I re-engaged with the academic world, reading, listening, talking, and writing, I reflected on the experiences that provided me with the energy for this stage of the journey and realized there was a story I needed to tell, one that embodied the power of professional collaboration, trust and curiosity.

\section{Why Collaborate?}

Collaboration is regarded as an essential component of professional learning and educational reform internationally, nationally, and provincially (Fullan, 2007; Hargreaves \& Fullan, 2012; Hargreaves \& Shirley, 2009). Internationally, countries look to one another's education systems, seeking solutions and insights, navigating between a desire to climb the scale on traditional international assessment measures while wrestling with the complex changes in the ways humans interact, create, and participate in society. As Zhao (2017) writes:

Human society is entering a new age marked by swift technological change, as well as rising challenges such as environmental degradation, the displacement of human workers by machines and widening inequality. We need to invent a new education paradigm that can cultivate uniquely creative and collaborative individuals to meet these challenges and take advantage of the new opportunities.

We, also, need to support and empower uniquely creative and collaborative teachers who can model, inquire, create, and share these skills in systems that can respond to both challenges and opportunities. The works of Lieberman (2005) and Seashore Louis and Kruse (1995), among other scholars, describe the need for teachers and school leaders to be able to adapt to changing conditions in order to educate young people in this rapidly changing digital world.

The need for collaboration is not only being considered in international contexts; the Council of Ministers of Education, Canada (CEMC, 2017) also emphasizes the imperative of working collaboratively in an interdependent world in the following:

A clear and relevant definition of global competencies for students in the pan-Canadian context is absolutely essential to support future discussions on fostering and measuring these competencies across provincial and territorial education systems. To that end, ministers have endorsed the following six pan-Canadian global competencies:

- critical thinking and problem solving

- innovation, creativity, and entrepreneurship

- learning to learn/self-awareness and self-direction

- collaboration [emphasis added]

- communication

- global citizenship and sustainability.

In British Columbia discourse, collaboration is also emphasized. Over a decade ago, the Office of the Auditor General of British Columbia (2003) noted: 
The importance of collaboration in education has been well documented in education reform literature. Developing capacities to support collaboration within and across communities provides opportunities to gain the shared knowledge and understanding necessary to develop and build upon a collective vision of realizing sustained education improvement. Communities that recognize the importance of collaboration understand that collective knowledge can generate new ideas, create group cohesion around a shared purpose, and foster a learning organization. (p. 8)

Despite these endorsements, deep and meaningful collaboration is not well understood, supported, or nurtured in schools and other educational settings, and is sometimes dismissed or disparaged, either implicitly or explicitly. Top down leadership models, pressure from disaffected colleagues, and structures designed for industrial efficiency (such as rigid schedules, bells, and classroom space characterized by desks in rows) can sap energy from the efforts of those committed to working together. Tensions between the development of collaborative communities for professional growth and learning within the context of structures and hierarchies designed for individualism are a complex reality to be negotiated. Educators need to find and create supports for collective endeavours. We need to find our ways to collaborate with our peers, model it in our classrooms, and teach it to students within, around, and through sometimes inhospitable environments.

As I considered this tension from my current vantage point as a doctoral student interested in professional learning and collaboration, I found myself returning to those early years of teaching, when I had the opportunity to experience professional growth through a collaborative endeavour. I connected with my two colleagues, Wendy and Brenda, who were so much a part of this story, and asked their permission to write about our time working and learning together. They came back with a resounding "Yes!" It was through the writing of this essay that I came to understand the profound experiences we had 30 years ago. The story of that time is woven in italics throughout this paper.

In 1986, parents, teachers, and district staff developed a shared vision for a model that was intended to support collaboration between colleagues and students, and integration of courses and disciplines. It was designed to support student voice and choice in learning, realizing the belief that students learn in different ways, and at different rates. Students in this program (which would exist within a conventional comprehensive high school) would be with each other and their teachers for multiple blocks, allowing for teaching and learning to be unencumbered by the traditional block and bell schedule. Rather than distinct "blocks" of time for each subject, a model ubiquitous in high schools, students and teachers would work together for the equivalent of half their timetable, exploring English, Social Studies, Math, and Science in interdisciplinary, organic, and shared ways. In addition, actively attending to lifelong learning skills including creative thinking, critical thinking, and problem solving, collaboration, and communication, were intended to serve as through lines, weaving throughout the subjects.

Looking back on this time through the intervening decades has helped me realize how innovative these ideas were, and how hard won those victories of valuing flexibility over scheduling must have been. It was the collaborative work of parents advocating for choice, teachers inspired by new ways of doing things, and district staff willing to 
support the vision by allocating the necessary space and resources that allowed the program to materialize.

The program started the same year I began teaching at the school, and, although I was not involved in its first year of implementation, I was hopeful for its success and watched with interest, as those involved worked together to navigate inhabiting a space of emergence within a traditional high school setting.

An important aspect to this vision was to conceive of learning through organic, rather than mechanistic metaphors (Davis, Sumara, \& Luce-Kapler, 2008). More than the sum of its parts or a series of steps that result in understanding, learning is inextricably interwoven with other systems in a continual and adaptive "dance of change" (Davis, Sumara, \& Luce-Kapler, 2008, p. 77). My notion of within, around, and through emerges from the natural world, recognizing the organic nature of learning, a complex and constant negotiation of certainty and uncertainty, and of knowing, unknowing, and coming to know. In the living world, a stream or a root will negotiate an impediment, and a seed will come to flower in a seemingly inhospitable environment. If learning is seen as adaptive and organic, education reform is possible when we focus on the stories of those who find their ways within, around, and through to imagine a way forward. Margaret Wheatley (2017) describes it this way:

What distinguishes living systems from machines is their ability to learn...A healthy living system is a good learner and can thrive even though its environment is moving toward increasing disorder. But to do so it must be actively engaged and aware. (p. 29)

Collaboration allows for an evolving understanding of the needs of engaging in a collective enterprise. Meaningful change requires meaningful collaboration, and meaningful collaboration requires trust and curiosity.

\section{The Role of Trust}

Trust is a precondition for collaboration (Lewis, 2006). Cloke and Goldsmith (2002) report that the more school leaders emphasize the bureaucratic elements of organization (policies, rules, regulations, and authority), the more satisfaction, creativity, commitment, and motivation are sabotaged. Embedded in this notion are implicit assumptions about distrust and trust, what Tschannen-Moran (2009) describes as bureaucratic orientation (implicit distrust of teachers through a command and control leadership model) versus professional orientation (implicit trust that teachers will utilize their knowledge, skills and dispositions autonomously to work to improve student learning). For those working in an organization with a bureaucratic orientation, collaboration occurs in those spaces not occupied by oppressive policies and authority. These collaborative spaces then become up to individual teachers to nurture in less formal ways - to find opportunities within existing structures to do the work of working together.

Bryk and Schneider (2002) identify four components of trust: respect, professional competence, personal regard for others, and personal integrity. Each of these informs the work of meaningful collaboration and must be acknowledged and embedded in the work of school improvement and was evident in my experiences from 30 years ago, described previously in this paper.

One critical element of respect is the belief that individuals "are being deeply listened to and understood" (Kaser \& Halbert, 2009, p. 50). A key indicator of respect is how discourse is 
structured within a community (Bryk \& Schneider, 2002), and how people connect and talk together, both formally and informally. Collaborative endeavours without respect will be superficial and meaningless. Whatever the means of collaboration, respect allows for open exchanges where people can examine their practice and learn together, and an emotionally safe space to ask questions and to explore complexity and tensions.

Trust requires the ability to listen. Attentive listening shows genuinely that what someone has to say is important and worth hearing. It is through listening that we can attend to others' perspectives, encourage them to give voice to their ideas, and provide the space to hear diverse views.

Bryk and Schneider (2002) describe the act of listening this way: "A genuine sense of listening to what each person has to say marks the basis for meaningful social interaction" ( $p$. 23). Too often conversations, even those around education reform and change, are solution oriented, dealing with solving the most immediate problem, or covering items on an agenda. Fullan (2007) stresses that learning communities must "foster an open exchange where teachers can explore elements of their own practise that they see as ethically responsive or problematic" (p. 50). These are difficult, and sometimes painful, conversations. When people feel heard and acknowledged, they can begin to share their stories. The following is the story of how I came to understand the importance of listening.

One of my most meaningful collaborative experiences began in my second year of teaching, but my first year at this particular school. It began, as many relationships do, in a serendipitous exchange. My colleague, Wendy, also in her first year at this school, joined me in the photocopy room. And in that space that occurs as two people are waiting, she asked me how thing were going, and, as we were waiting for the photocopier to finish, I told her. And she listened. Her willingness to be silent and to listen began our professional journey together.

My own story of collaboration began with a colleague's willingness to listen, to create the respectful space for me to answer a question fully.

Professional competence is the second element of trust and is key to meaningful collaboration. This competence is characterized by a shared sense of purpose, with a collective focus on student learning (Seashore Louis, Kruse, \& Marks, 1996). Teachers are required to apply their professional judgement in situations within ethical expectations, codes of conduct and standards of practice. However, in schools with bureaucratic leadership models leaders "do not trust teachers to make responsible, educationally appropriate judgements" (Darling-Hammond, 1988, p. 63). This lack of belief in teachers' professional competence erodes trust and limits collaboration, as Darling-Hammond (1988) describes in the following:

Norms of inquiry and ethical conduct are extremely important. But because knowledge is constantly expanding, problems of practice are complex, and ethical dilemmas result from conflict between legitimate goals, these requirements cannot be satisfied by codification of knowledge, prescriptions for practice, and unchanging rules of conduct...these norms must be accompanied by socialization to a professional standard that incorporates continual learning, reflection, and concern with the multiple effects of one's actions on others as fundamental aspects of the professional role. [emphasis added] (p. 67) 
Darling-Hammond's findings connect professional competence and respect with trust. Teachers, working together in mutually meaningful ways, create opportunities to explore their professional commitment and growth in highly complex situations.

Paradoxically, vulnerability is an important consideration in developing competence. Bryk and Schneider (2002) conclude "the key operational feature of a school community is not its power distribution, but rather a set of mutual dependencies and, with them, mutual vulnerability" (p. 183). Those with the most power in a situation must be willing to show vulnerability first, something unlikely to happen in a highly hierarchical organization with a leader who has an authoritarian orientation.

However, when vulnerability is demonstrated, when those with whom we work acknowledge they are puzzled or challenged, meaningful conversations can occur. Kruse, Louis, and Bryk's (1995) work identifies five elements of successful learning communities: reflective dialogue, deprivatization of practice, collective focus on student learning, collaboration, and shared norms and values. They go on to emphasize the social and human resources required in learning communities, which include openness to improvement, trust and respect, and a strong cognitive and skill base. These resources require professional competence, expressed through knowing, unknowing (a willingness to let go of ideas that no longer serve), and coming to know.

As Wendy and I listened and talked, we were able to articulate the challenges of connecting our practice with our ideals, and identify organizational constraints on realizing these ideals. We were exploring our commitment to the profession. Our growing mutual respect allowed us to engage in honest conversation, and our interest in growing our professional commitment fueled our conversations. The questions we explored together and formed the basis for our collaboration included the following: Was what we were teaching worthwhile and meaningful? Were we making a difference? What gets in the way of improving our practice and how do we work our way through those things?

Wendy had been hired to teach in the new integrated program, and she invited me in to her classroom to explore whether this flexible learning environment provided more authentic learning opportunities for students than the traditional system in which I was teaching.

The following year, I joined her as part of the integrated program team, a Humanities teacher (me), a Math teacher (Wendy) and a Science teacher (Brenda). The three of us took the curricular expectations and determined where we could integrate, blur, or remove disciplinary boundaries, and how we could use the larger blocks of time to students' advantage by organizing learning experiences outside the school, taking the time we needed for a concept to be taught and practised, and for students to rework assignments if they did not receive the results they had hoped for.

The pushback from some other staff members was swift. Some advocated for us buying our own texts and resources (we were "hogging"), others felt students in our program were not "playing fair" if they received higher marks after reworking an assignment or projects, still others objected to students working together in the hallways and corridors. 
Through these interactions, our team would regroup and ask ourselves if what we were doing was in the service of the students' learning and growth. We were constantly in positions of needing to justify our actions and decisions, and as relatively new teachers, we continually questioned ourselves. It was our respect for one another and the students we taught, and our commitment to working in ways we believed would support students in success (both academic and in learning the skills needed for life-problem solving, being responsible for choices and decisions, working together) that kept us going.

We were challenged to make our ways fit the conventional ways-the timing and format of report cards, the criteria for awards, punishments for late assignments, the expectation of department and provincial exams. And still we kept working together, finding our ways within, around and through.

Our emerging understanding of professional competence as a commitment to our professional standards and a willingness to explore what we did not know allowed for what Tschannen-Moran (2009) identifies as openness that "allows collective problem finding and problem solving to characterize the professional dialogue" (p. 229).

The third element of trust is personal regard for others, the belief that others care about us and are willing to "extend themselves beyond the formal requirements of a job definition or a union contract" (Bryk \& Schneider, 2003, p. 42). In situations of low trust, micro-managing becomes a way to exert control over others' actions. Cloke and Goldsmith (2002) found that this encourages a culture of dependency, one that interferes with professional growth. Trying to control variables through micro-managing results in alienation and lack of commitment, exactly the reverse of what is needed for trust and collaboration. Furthermore, Tschannen-Moran (2009) describes the control paradox, where the more leaders try to control through rules and policies, the more resistance and resentment builds. In fact, Solomon \& Flores (2001) discovered that while teachers may outwardly comply with this control structure, they will find ways to sabotage leaders' efforts, using their creative efforts in ways that undermine rather than support.

A trust orientation builds on the notion that professionals work beyond the job description or contract, and that this is an intrinsically motivated choice. Building the personal regard that emerges from this trust orientation takes time. It takes witnessing and acknowledging behaviours over many occasions to see the situations when individuals go above and beyond with students or colleagues, where people demonstrate this internalized commitment to the professional role.

Because Wendy, Brenda, and I spent so much time together with students, we witnessed each other's commitment to the work we were doing together, which further increased our personal regard for each other. Our conversations and collaborative efforts required that we shared perspectives, information, and ideas, and that we problem solved together. A student concern became an opportunity to examine our practice, to determine our part in creating or ameliorating the situation.

We also came to know the students better. We were with them for half the school day, and saw them in a variety of contexts. They were writing and performing plays, helping one another in math, working in multi-aged groups, working with us in one-toone and small group situations. And Brenda, Wendy, and I watched and learned from one 
another as we saw how we interacted with students, designed curriculum, planned for activities, and considered assessment practices.

We saw evidence and examples of each other's work inside and outside the classroom. Advocating for the students, working together to create meaningful learning experiences, figuring out how to work within, around and through existing paradigms, brought out in each of us an increased regard for the others.

Students also shared with us their frustrations and successes, how Flex was challenging, what structures were working, and what got in the way. They became advocates, talking to other students, teachers, and school district officials about why the program worked for them and how this community was making a difference.

An unintended benefit was that students learned how teachers talked about pedagogy and purpose. They were witness to, and participants in, discussions about how and why we organized, what mattered to us fundamentally and how we enacted (or didn't) the philosophies of the program.

This personal regard for one another, coupled with our commitment to developing our competence and our mutual respect, strengthened our commitment to our partnership and our program.

Integrity, the final element of trust (Bryk \& Schneider, 2002), is the product of consistency between our words and actions. It also connects with the competence element of trust in that, when inevitable frustrations or disagreements arise, our actions and decisions must maintain integrity with the underlying principle of supporting students. Darling-Hammond (1997) elaborate on this point, writing, "When all is said and done, what matters most for students' learning are the commitments and capacities of their teachers" (p. 293). Integrity is the desire and commitment to act in ways that puts the learning of students at the centre.

The quality of support systems allows individuals to cultivate and demonstrate integrity. If school leaders are not seen as having integrity, there is a resulting lack of trust in these leaders and an even further result of stifling communication. Tschannen-Moran (2009) writes:

In addition, differential levels of trust can affect patterns of communication between levels of a hierarchy. When one is interacting with a distrusted person within an organizational hierarchy-especially if that person holds more power-the goal of communication becomes the protection of one's interests and the reduction of one's anxiety rather than the accurate transmission of ideas...Specifically teachers have described being guarded in what they said - that they often blocked or distorted communication to avoid confrontation with colleagues and administrators. (p. 222)

Distrust is not a condition in which collaboration can flourish. The energy of individuals is directed at protecting themselves from situations of distrust by focusing on self-interest, rather than energy being directed outward to explore, share, and improve alongside colleagues and school leaders.

Tschannen-Moran (2009) describes school leaders as those who demonstrate integrity and "a professional orientation, not only structure work processes but cultivate norms that enable teachers to productively engage in collective inquiry and constructively contribute to student 
needs" (p.11). When conflicts arise, and they will, integrity focuses the energy on shared understandings rather than personal victory:

In adjudicating these disputes, integrity demands resolutions that reaffirm the primary principles of the institution. In the context of schooling, when all is said and done, actions must be understood about advancing the best interests of children. Teachers demonstrate such integrity to their colleagues when they willingly experiment with new forms of instruction to promote student learning, even though this entails additional work and the risk of failure can be high. (Bryk \& Schneider, 2002, p. 26)

There were inevitable conflicts. Frustration and fatigue did not call the best out in us. It sometimes felt as though we were battling on all fronts, justifying our practice at the same time as we questioned it, putting in extra hours to find time and space where we could plan together while watching others leave for home. What pulled us back together was that one of the three of us would ask two questions: "Are we doing what we feel is in the best interests of the learners?" and "What can we take on now, and what can wait?"

The ability to telescope from the big picture to the details and out again was a powerful outcome of our collaboration. The camaraderie we had, along with the trust we had developed, allowed this rich conversation between the ideal and practical, focusing our energies on keeping true to the philosophy of the program. Debriefing the joys and struggles fueled our conversations. We were engaged, although we would not have named it as such at the time, in reflexive practice.

We decided to ask for feedback from parents and students in the program and held a series of formal and informal sessions to discover whether our philosophy of the program was enacted in what we were doing, and if parents and students had the same conceptions of the purpose of the program.

The three of us made a conscious decision to resist defending or becoming defensive if ideas and opinions were different from our own. We framed the discussion around exploring and recommitting to the fundamental principles of the program, and determining if our practices aligned with these principles. What we discovered was that parents and students felt we were not challenging the current educational models enough. What we thought might be pushback from our ideas actually turned out to be a renewed energy for further exploring what the program could do and be. Parents and students were not behind us; they were waiting for us to catch up.

\section{The Role of Curiosity}

To develop trust, those who work together must demonstrate the characteristics of respect, professional competence, personal regard for others, and integrity. However, trust alone does not create learning communities. These attributes take time to become known in a fast-paced, complex, and sometimes isolating profession.

In many schools, the desire for professional autonomy has contributed to this isolation. This view of professionalism, one that equates autonomy with independence, fails to recognize the interdependence between "bodies and minds, selves and others, individuals and collectives, knowers and knowledge" (Davis, Sumara, \& Luce-Kapler, 2008, p. 98). Fullan (2007) also emphasizes the need to breakdown autonomy: 
Teachers and teacher leaders will have to take some risks here. It is one area that is both powerful and within the control of teachers: break down the autonomy of the classroom so that greater consistency of effective practice can be achieved. (p. 56)

Although students surround teachers almost all day, the act of teaching can feel quite lonely. It is not that teachers necessarily want this isolation. Many express a real desire to interact with colleagues at times other than formal meetings or during lunch hour. They express envy when teacher candidates are encouraged to observe widely, in different learning spaces in the school, and outside of their disciplinary areas, since for most teachers, what goes on in other teachers' classrooms is a mystery. A former colleague described it this way: "Sometimes being a teacher feels like being an egg in a carton; we are each in our own container in a manner that seems well-organized, but is actually isolating for teachers and endlessly replicating for students" (D. Norris-Jones, personal communication, September 22, 2015). School leaders have the capacity to support their teachers' desire to work collegially by considering organizational changes, such as the arrangement of time to allow for collaborative planning. However, structural change alone will not necessarily increase collaboration. Curiosity about improving our practice through collaboration can draw us outside our classrooms to learn in community.

Just as I deliberately chose to use the term collaboration as opposed to professional learning communities, I am deliberately using the term curiosity instead of the currently popular term inquiry. Inquiry runs the risk of becoming another trend, the downside of which is the adoption of the term without a deep understanding of, or commitment to, the process. Curiosity is a habit of mind more than a series of steps or a plan to implement. Kaser and Halbert (2008) describe this process as a mind-set that "helps build capacity in school for lasting improvement and a spirit of inquiry rather than the adoption of a specific program encourages teacher curiosity and a sense of agency" (p. 55).

Curiosity is the genuine desire to learn more, to investigate, to explore, and to challenge. Kaser and Halbert (2009) found that "the strongest school leaders are characterized by constant curiosity and a mindset of persistent inquiry" (p. 62). Curiosity flourishes in environments built on trust.

Change involves learning to do something new, and interaction is the primary basis for social learning... New meanings, new behaviours, new skills, and new beliefs depend significantly on whether teachers are working as isolated individuals or are exchanging ideas, support, and positive feelings about their work. The quality of working relationships among teachers is strongly related to implementation. Collegiality, open communication, trust, support and help, learning on the job, getting results, and job satisfaction and morale are closely interrelated (Fullan, 2007, p. 97).

Fueled as much by emotion as by intellect, curiosity emerges through a genuine interest to understand more fully and explore more deeply. Cherkowski (2012) writes:

Deep human capacities - such as love, joy and compassion - in the daily work of formal school leaders and teachers are more explicitly noticed, appreciated, and recognized as important components for fostering and sustaining teacher commitment for professional growth in learning communities. (p. 58) 
Curiosity stems from desiring to know differently rather than from a mindset of already knowing. As teachers become curious, they come to recognize the complexities of learning: "For complex learning systems, equilibrium is death, whereas operating far-from-equilibrium forces them to explore their spaces of possibility" (Davis, Sumara, \& Luce-Kapler, 2008, p. 8).

A spirit of curiosity helps us cope with, and adapt to change. No matter how welcome, change requires a shift. "All real change," wrote Schön (1971), “involves passing through the zones of uncertainty...the situation of being at sea, of being lost, of confronting more than you can handle" (p. 12). Real change requires a shift in teachers' thinking about their role. Professional knowledge and competence is essential for teachers, as is the realization that these skills change over time and as a response to changing situations and new experiences. We must be adaptive, and part of our competence is learning when we need to change. As we learn and grow, our energy needs to be directed to new ways of teaching rather than in "sustaining an unrealistic expectation that [we] are to appear the most knowledgeable people in every situation" (Office of the Auditor General, 2003, p. 7).

When we put ourselves in situations that recognize this disequilibrium, trust-in our colleagues and ourselves - is essential. It requires that we approach these uncomfortable situations with a genuine attitude of curiosity. In fact, our beliefs and behaviours must work in concert, as we stretch and challenge each, coming to learn by thinking and doing. Fullan (2007) indicates the necessity to: "address [beliefs and behaviour] on a continuous basis through communities of practice and the possibility that beliefs can be most effectively discussed after people had had at least some behavioural experience in attempting new practice" (p. 37).

As behaviours affect beliefs, continued collaboration will sustain the energy to explore new methods and approaches and the conversations that occur as a result. Knowledge can be shared and practice can be deprivatized. This nesting of knowledge and practice within collaborative communities of practice allows for continual innovation and improvement and a nimble response to change. The social and intellectual support that professional communities offer provides a real opportunity for paradigm shifts:

If teacher commitment is conceptualized more broadly as the desire to continue to grow and learn within a professional community of colleagues, the connection between teacher commitment and sustainable learning communities becomes quite clear. Sustaining vibrant learning communities requires more than teachers' commitment to remain within the organization - it requires a commitment to continued growth and learning that is shared with colleagues. (Cherkowski, 2012, p. 57)

Wendy, Brenda, and I worked together for several years. The time we spent together only increased our trust in our working relationship and inspired our curiosity. Watching each other work with students expanded our repertoire of strategies. We continued to explore ideas, such as moving beyond integrating English and Social Studies into Humanities, to making connections between Math, Science, and Social Studies. What we had previously seen as discrete, decontextualized subjects became fertile ground for integration. We used one another's strengths to strengthen our pedagogy. When we found overlaps and connections, we explored ways to embed these in our teaching. We became increasingly curious about one another's subject areas though we had previously been intimidated. 
As the program developed, we consciously worked on balancing the disciplinary curriculum with the process curriculum, working with students to practise problem solving, foster community, and develop teams of students across grades. We were working with students to develop the skills we were still exploring: how to collaborate, trust one another, and maintain a spirit of curiosity during changing times. Out of a conversation between two teachers in the photocopy room had emerged a vibrant "school within a school" for 120 students. What had also emerged was a renewed professional commitment to working collaboratively to improve our practice.

As personnel changed, due to a variety of circumstances, we wondered what would happen to our practice and to the program. We knew we would need to adapt as new colleagues came to work with us, and that the program would have to adapt and change to respond to changing contexts. As we moved on to new endeavours, would we continue to collaborate with new colleagues in new environments? Would we find trust and community that helped to feed our curiosity? Would the program thrive? Would others come and continue to work with the students in their own collaborative endeavours? I can happily report that the answer to all these questions is "Yes," thanks to those teachers who continue to commit to the hard work of working together.

\section{Conclusion}

The world continues to change, with or without change in our education paradigms. However, student learning and the quality of the learning environment will become increasingly compromised if we do not adjust how we work and learn together in ways that more profoundly reflect the reality that humans need to work in collaborative, supportive, respectful, trusting, relational ways and to recognize new conceptions of learning grounded in complexity. Collaboration, built on trust and curiosity, can create environments that are responsive, adaptive, and proactive. Whether or not the existing conditions support or constrain our collaborative efforts, we can find space within, around, and through to one another. "If we are to work together more intelligently, we will need to choose processes that evoke our curiosity, humility, generosity, and wisdom. The ultimate benefit is that we learn that it is good, once again, to work together" (Wheatley, 2005, p. 124). 


\section{References}

Bryk, A., \& Schneider, B. (2002). Trust in schools: A core resource for improvement. New York, NY: Russell Sage.

Byrk, A., \& Schneider, B. (2003). Trust in schools: A core resource for school reform. Educational Leadership, 60 (6), 40-44.

Cloke, K., \& Goldsmith, J. (2002). The end of management and the rise of organizational democracy. San Francisco, CA: Jossey-Bass.

Cherkowski, S. (2012). Teacher commitment in sustainable learning communities: A new "ancient" story of educational leadership. Canadian Journal of Education, 35(1), 56-68. Retrieved from: http://journals.sfu.ca/cje/index.php/cje-rce/issue/view/88

Council of Ministers of Education, Canada. (2017). Global competencies. Retrieved from https://www.cmec.ca/682/Global Competencies.html

Darling-Hammond, L. (1988). Policy and professionalism. In A. Lieberman (Ed.), Building a professional culture in schools (pp. 55-57) New York, NY: Teachers College Press.

Darling-Hammond, L. (1997). Doing what matters most: Investing in quality teaching. New York, NY: The National Commission on Teaching and America's Future.

Davis, B., Sumara, D., \& Luce-Kapler, R. (2008). Engaging minds: Changing teaching in complex times $\left(2^{\text {nd }}\right.$ ed.). New York, NY: Routledge.

Fullan, M. (2007). The new meaning of educational change (4 $4^{\text {th }}$ ed.). New York, NY: Teachers College Press.

Hargreaves, A., \& Fullan, M. (2012). Professional capital: Transforming teaching in every school. Toronto, ON: Teachers College Press.

Hargreaves, A., \& Shirley, D.L. (2009). The fourth way: The inspiring future for educational change. Thousand Oaks, CA: Corwin Press. Retrieved from http://dx.doi.org/10.4135/9781452219523.n1

Kaser, L., \& Halbert, J. (2008). A cross-grade learner conversation. In L. Earl and H. Timperley (Eds.), Professional learning conversations (pp. 53-68). New York, NY: Springer.

Kaser, L., \& Halpert, J. (2009). Leadership mindsets: Innovation and learning in the transformation of schools. Oxford, UK: Routledge.

Kruse, S., Louis, K., \& Bryk, A. (1995). Building professional learning in schools. Madison, WI: Center on Organization and Restructuring of Schools.

Lewis, K. S. (2006). Changing the culture of schools: Professional community, organizational learning and trust. Journal of School Leadership, 16 (5), 477-489.

Lieberman, A. (Ed.). (2005). The roots of educational change: International handbook of educational change. Dordrecht, NL: Springer. 
Office of the Auditor General of British Columbia (2003). Changes, choices and challenges: Building capacity for continuous improvement in the B.C. public education system. Updated audit proposal. Victoria, BC: Office of the Auditor General.

Schön, D. (1971). Beyond the stable state. New York, NY, Norton.Seashore Louis, K., \& Kruse, S. (1995). Professionalism and community: Perspectives on reforming urban schools. Thousand Oaks, CA: Corwin.

Seashore Louis, K., Kruse, S., \& Marks, H. M. (1996). School-wide professional community: Teachers' work, intellectual quality, and commitment. In F.W. Newman \& Associates (Eds.), Authentic achievement: Restructuring schools for intellectual quality (pp. 179203). San Francisco, CA: Jossey-Bass.

Solomon, R. C., \& Flores, F. (2001). Building trust in business, politics, relationships, and life. Oxford, UK: Oxford University Press.

Tschannen-Moran, M. (2009). Fostering teacher professionalism in schools. Educational Administration Quarterly, 45 (2), 217-247.

Wheatley, M. (2005). Finding our way: Leadership for an uncertain time. San Francisco, CA: Berrett-Koehler.

Wheatley, M. (2017). Who do we choose to be? Facing reality, claiming leadership, restoring sanity. Oakland, CA: Berrett-Koehler.

Zhao, Y. (2017, September 6). Fatal attraction: Why copying each other won't improve education. Retrieved from http://zhaolearning.com/2017/09/06/fatal-attraction-whycopying-each-other-wont-improve-education/ 